\title{
Research on Production and Innovation of Contemporary Chinese Animated Films
}

\author{
Bo Zhang ${ }^{1}$ \\ ${ }^{1}$ Department of Art and Design, Shanghai Publishing and Printing College, Shanghai, 200093, China
}

Keywords: Animated film, Film production, Film creation

\begin{abstract}
From the perspectives of the quantity and quality, the development of Chinese animated films has made brilliant achievements in recent years. Chinese animated films have made outstanding achievements in the aspects of styles diversification and products serialization. This paper summarizes the main production points of outstanding animated films in contemporary China, including role modeling, plot design and music coordination, and gives the innovation directions of contemporary Chinese animated films to provide some references for the relative researchers.
\end{abstract}

\section{Introduction}

The rapid development of China's movie market has opened a huge space for the development of China's animated films [1]. The huge demand for the market and the number of excellent domestic animated films become the urgent need for the industry to solve. In the industrial environment where capital has absolute discourse power, quick success and instant benefit are the reasons for the emergence of many low quality animated films. Plot design is a short board commonly existing in China's animated films. As an important factor affecting the audience's vicarious experience, the quality of plot design is the object that animated film creators need to consider. "Contemporaneity" is an adaptation, an adaptation to contemporary social life, a universal value that divides time and pursues the characteristics of the contemporary era. The contemporary study of domestic animated movies refers to the rationality of nationalized style in contemporary society and the direction of transmission and development of domestic animated films: Based on contemporary life. This requires that the contemporary creation of animation film should first reflect the characteristics of the high speed development of science and technology, integrate the traditional culture into the modern advanced animation design and production, reflect the combination of the beauty of traditional art and the beauty of modern technology; secondly, pay attention to the spirit of contemporary discourse, and reflect the changes of the aesthetic psychology of the public and the popularization of culture. Background; once more, we should pay close attention to the background of economic and cultural globalization, conduct cross-cultural communication and learn from the advanced experience of foreign animation creation. In the twenty-first century, with the revival of national cultural awareness and the establishment of Chinese cultural coordinates, domestic animated films began to focus on the integration of traditional cultural elements, especially in recent years. With the development of domestic animation industry chain and the improvement of production level, a batch of animated films have achieved good reputation, from which the culture return of domestic animation can be seen [2].

\section{Production Points of Contemporary Chinese Animated Films}

\subsection{Role Modeling}

The role of Chinese animated films is obviously influenced by Chinese traditional culture [3]. Confucian culture has far-reaching influence in China, and the social responsibility it emphasizes has been integrated into the depth of our national spirit. The spirit of collectivism in the traditional Confucian culture. The concept of salvation is a common theme in animated movies, and it also 
incorporates natural elements in the shaping of roles. The image creation of Chinese animation characters is also deeply influenced by national traditional culture. The development of any form of art is inseparable from its cultural soil. It is closely related to the ancient national culture in the unique cultural atmosphere of China. Chinese folk art, such as paper-cut, New Year pictures and shadow play, can be used as inspiration source for animation role modeling. With the continuous development of the times and the continuous improvement of technology, animation movies are also developing constantly, so the shaping of roles should also keep pace with the times. Blindly immersed in the inherent and outdated aesthetic concepts is hard to get the recognition of the audience and will eventually be eliminated by the times. The Role Portrayal of Chinese animated movies must have distinctive national characteristics, as well as the spirit of the times. Only in this way can we create classic animation characters. Besides, the domestic animated films cannot be self-complacent. They should constantly absorb and utilize advanced elements in other cultures to achieve their purpose. There are great differences between eastern and Western cultures. Oriental culture is characterized by introverted and implicit features. In contrast, western culture is open and tolerant, which also influences the character creation of animated characters. The polarized character is hard to arouse the audience's sympathy, so the role loses charm. The protagonists are not perfect. They are easy to give the audience the intimacy and charm of their roles.

\subsection{Plot Design}

The content of animated movies can be summarized as two aspects: sensory level and logical level. In the film, all the elements that can be seen and heard belong to the content of the sensory level, and the content of the logical level refers to the content that must be understood through the perception and understanding of the audience, such as the relationship of the characters, the motive of the behavior, the plot, the subtext and so on. At present, the domestic animated films have accumulated much experience in improving the sensory content quality, showing a trend of increasing year by year. The weakness of logical content design is a common problem in domestic animated films. The story is not good enough, which has always been a topic of criticism for audiences. Therefore, we need to tell a good story to make audiences like them. The movie story is the audience after viewing the story to convey the overall evaluation of the film. For the audience of the first view, the high-quality sound and painting effect, the impressive role modeling, vivid and vivid performance, and the clever plot design are the reasons for the interest of the audience. Among them, let the audience produce emotional resonance and strong alternative experience is the two key elements of role modeling and plot design. In addition to the requirements of the role of vivid characters, prominent features, also show vivid characters. But the performance of roles is not an isolated existence, so the cause of role action is an event. In summary, events lead to motivation, motivation, action and action. A story is composed of a series of motivations that are causally related and linked, and these events are a series of episodes. Therefore, the stereoscopic and life role modeling and story plots are intertwined, complementary and interdependent. The action points to the animation noumenon, and the plot is closely related to the story telling function of the script. The key to the animated script is to maintain an intersexual relationship between the description of the action and the advance plot. The core elements of animated films are audiences' interesting movies and elaborate plots [4].

\subsection{Music Coordination}

The nationalization of the music of Chinese animated movies is the vivid portrayal of the transformation of Chinese society from the modern nature to the Chinese modernity, and finally to the creation of the film. The concept of modernity is the import of western culture to China. It is the historical inheritance of the world from the independent and closed small unit to the integration. Some culture with strong invasion ability and molding ability reshaped the native culture bred in other regions. As a continuous development and irreversible objective existence, the birth and dissemination of modernity profoundly influenced the world we live in. Under its influence, the national state has gradually formed, and has formed a new social structure based on the concept of national state with the model of his country as a model. Modern political concepts and modern legal systems have been constructed in the gradual process of nation-state development. Objectively 
speaking, this trend of development brings the mental suffering and physical pain of the nation-state, but also promotes the development of the whole society. In the development of early Chinese animated movies, the issue of nationalization of music has been paid enough attention, but the film workers mainly define the music elements in animated films from the angle of auxiliary means. This makes the problem of music nationalization in Chinese animated movies too generalized and does not return to the animated movie itself. "Music can excavate and enhance the inner character of a character. It envelops the specific atmosphere of the scene: terror, magnificence, joy or misery. The dull dialogue rises to a poetic realm after music. Only by giving full play to its role in music can the movie's artistic value be fully released. We should also recognize that music is the common spiritual wealth of the world. Only by broadened our mind to meet the achievements of Western civilization can we provide impetus for the development of our national culture.

\section{Innovation Directions of Contemporary Chinese Animated Films}

\subsection{Visual Impact}

The reason why art works can attract viewers and convey beauty is the visual impact produced by the rich connotation of visual language symbols. The animated cartoon relies more on the artistic technique of painting aesthetics. Through the painting language of point, line, face, body, color, material and so on, the cartoon depicts the animation image and atmosphere that conforms to the emotional logic, so that the audience can get the understanding and feeling of thinking and emotion at the same time of satisfying the visual aesthetic. Chinese animation movie people feel the beauty of artistic expression while they feel the fun of animation story. Animation is one of the most diverse forms of art in the form of expression. All the art means and materials such as watercolor, sketch, oil painting, sculpture and any other material can become the form elements of the animation and arouse the creative inspiration of the animator. With the involvement of computer digital mapping technology, many unimaginable visual effects can be realized, making the form of animation more diversified. As an aesthetic object, the animated image itself is full of strong sense of beauty and has more visual impact. Animation color in the animation picture through the rendering of the natural environment, through the description of the architectural landscape and the role of the image, enriches the expression of the animation picture language, can play the overall atmosphere, enhance the impact of visual impact and artistic appeal. Chinese traditional painting has rich color language and distinctive style, which provides abundant resources for the design of animation color. Unlike western paintings, which focus on the pursuit of the sense of reality, Chinese paintings pay attention to the expression of the author's emotions through rich and varied colors and colorful pigments. These elements also fit the aesthetic requirements of the audience and are widely used in the production of animated films.

\subsection{Aesthetic Pursuit}

In the process of aesthetic, people's psychological activity is rather complex comprehensive reflection, it is the whole function of the brain, and its feeling, thinking, understanding and imagination are forming and forming psychological mechanism. The reason why the cartoon image can be perceived as the object of the aesthetic is because the role of the character stimulates the sensory organs of the aesthetic subject in the form of beauty and brings physiological pleasure and spiritual pleasure to the audience. The aesthetic subject should use his original life experience and knowledge, take it into the object of aesthetic, arouse all kinds of association and imagination of things, and make people feel and beauty. Artistic conception is the core category of Chinese aesthetics. It refers to the artistic realm formed by the integration of aesthetic experience, emotion, ideal and creative image. The artistic conception is the unity of the meaning and the mood, the feeling and the scene. Appreciate the face scenes of the unique atmosphere and rich connotation of art space, can arouse imagination in emotional resonance. Paying attention to the aesthetic psychology and demand of the audience is an important part of the research of Chinese animation aesthetics. The animation creation should grasp the changes of the aesthetic psychology in the audience's view, 
distinguish the age and cultural background of the audience, and pay attention to the changes of the certain context, the times and the social, political and economic trend of thought. The main audience groups of animated movies are children and teenagers. In view of their unique thinking mode, animated movies should focus on the artistic expression of animated images. Only the image with visual impact can first attract the eyeballs, while the past animated films pay too much attention to the narrative function and teaching function of language. The characteristics of animation art cannot combine entertainment with education very well.

\subsection{Humanistic Concern}

If the theme implies that the animated film has the support of the backbone of the body, the strong humanistic concern is the expression of the rich emotional expression of the movie. Aesthetics is based on human studies. As an art form, animation movies should also take humanistic care as the value orientation. The animated image is inanimate, but the creative subject is integrated into his life experience and the understanding of life, and the dialogue between the artist, the audience and the life of the nature species is realized. Animators projecting and implanting their own emotional experiences into animated images. The imaginary spirits are touched, and the life rhythm of the animated image is compatible with the mind of the audience, and in a dreamlike art world. The humanistic spirit is a kind of universal human self-care, which is expressed as the maintenance, pursuit and concern of human dignity, value and fate, and highly valued the various spiritual and cultural phenomena left over by human beings. Humanistic concern is regarded as the soul of animated film creation. The successful animation film makers are all concerned about the reality. They are the thinkers of raising the animation to the high level of humanity, dreams, life, survival, environmental protection and other reflective problems, and ingeniously integrated into them. The work of Hayao Miyazaki, the director of Japanese top animation film, integrates his thinking about man and nature, including his love of life and love of nature, intertwined with his helplessness and incompetence in the imbalance between human and nature. The works are full of humanistic care with Hayao Miyazaki's personal color, but also of us. A subject that must be thought deeply. As the aesthetic subject, the creator and the audience group will put their own unique feeling and experience into the animated movies. Only enough and deep emotion will cause the audience to resonate.

\section{Conclusion}

In recent years, with the successful box office of several outstanding domestic animation films, with the idea of some excellent animation companies adhering to the production of excellent products, the production environment of domestic animation has been greatly improved. Capital has been concerned about the importance of the artistic value of films and has made great progress in the production of hardware and software and the production level of practitioners in China. Nowadays, Chinese filmmakers should grasp the innovation directions of visual impact, aesthetic pursuit and humanistic solicitude.

\section{References}

[1] Yu Miao. The Influence of Hayao Miyazakis Animated Films on the Development of Chinese Animated Films [J]. Journal of Liaoning Normal University (Social Science Edition), 2015, 38(4): 554-557.

[2] Qi Peng. Strategies of Constructing Culture Embodiment in Domestic Animation Films [J]. Journal of Qujing Normal University, 2017, 36(1): 101-104.

[3] Wang Xiage, Zhang Suqiu. Recent Situation of Imported Animated Films and Inspiration of them upon National Animated Films [J]. Hundred Schools in Arts, 2017(4): 88-93.

[4] Zhang Juan. A Summary of the Creation of Domestic Animated Films in 2016 [J]. Journal of Chengdu University (Social Sciences), 2018(1): 83-88. 